\title{
Regulation of the microecological environment of residential buildings in southern cities with a hot-calm climate condition
}

\author{
Adham Giyasov, ${ }^{1, *}$ \\ ${ }^{1}$ Moscow State University of Civil Engineering, 26, Yaroslavskoe shosse, Moscow, 129337, Russia
}

\begin{abstract}
The article studies one of the ways of passive use of solar energy, providing a favorable microecological conditions in the housing of southern cities with extreme hot-calm climate conditions. The ecological condition of the internal air environment of the premises is considered in connection with the ecological situation of the environment near the residential building. The role of gravitational convection of the wall layer of air in aeration and ensuring the ecological purity of the air in the premises of the buildings of southern cities is established.
\end{abstract}

\section{Introduction}

Proceeding from the criteria of ecological safety of the population living, provision of microecological comfort in the dwelling is one of the most important tasks of architectural and construction design. Dwelling - is a structural element of the city with a complex system of natural and artificially created environment, where effects of physical, chemical and biological nature are combined. Factors of physical nature include microclimate, insolation, illumination, dustiness, gas contamination, electromagnetic radiation, noise, vibration of technogenic origin. The quality of the microecological environment of residential buildings is regulated by building codes and regulations and a number of sanitary and hygienic standards for certain environmental factors. In designing a dwelling, the main task from the point of view of protecting the health of residents is to ensure microecological comfort, including through the heat efficiency of buildings and the protection of the air environment from contamination with harmful substances. In recent years, due to the deteriorating environmental situation, a person is trying to make every effort and opportunity to create an enabling environment. Most of our time, each of us spends in apartments, therefore, the issue of the ecology of an apartment should become a topical issue $[1,2]$.

\section{The formulation and method of solving the optimization problem}

In recent years, there have been significant changes in the construction of buildings, the device of the interior, using new building materials (plastic window blocks and blinds, non-

\footnotetext{
*Corresponding author: adham52@mail.ru
} 
natural carpets, furniture and household items) made of materials of organic chemistry. Often the most important factors determining the quality of indoor air are tobacco smoke, emissions from furnaces and stoves, radioactivity of some elements that make up the materials used in construction and etc.

Thus, the premises themselves become the source of all kinds of air pollution, which, in combination with radiation and thermal emissions from household appliances and people create environmental discomfort in the room. To ensure healthy living conditions for people, it is necessary to develop appropriate conditions for organized aeration of premises.

The decisive role in the formation of environmental comfort, including the air-thermal environment, has the removal of restrictions on the upper limit of the areas of apartments and a wider range of architectural and planning solutions. One of the main factors for creating ecological comfort is the correct air exchange (at least $30 \mathrm{~m}^{3} / \mathrm{h}$ per person) for the removal of polluted air and neutralization of the hazardous in the buildings. This value ensures the content of $\mathrm{CO}_{2}$ in indoor air within the permissible concentration $(0.1 \%)$ and determines the minimum hygienic level. Optimum conditions of the air environment $\left(\mathrm{CO}_{2}-0,05 \%\right)$ is achieved with air exchange of $60 \mathrm{~m}^{3} / \mathrm{h}$ per person.

The external surface of the walls of buildings is affected by heat from solar radiation upon their insolation and the heat flux of the outside air. The building surrounded by a wall layer of air (thermal envelope), depending on the insolation condition is inhomogeneous. If in the presence of wind the pressure difference between the wall layer of air and the premises is created by complex conditions of air flow around the building, then under the calm weather condition the cause of heterogeneity is the irradiation conditions of the facades of buildings, creating a temperature difference between the surfaces of the walls and the wall layer of air. At the same time, the heat head arises from the difference in the specific weights of the external and internal air. Depending on the thermal qualities of the building envelope, the solar radiation coming to them is transformed in different ways: reflected, emitted and absorbed, converted into thermal energy. The values of the latter determine the thermal state of the vertical walls, roofs and underlying surfaces of the adjacent territories, and as a result the power and mobility of convective flows in the area of the dwelling. Microecological shell of the building, along with solar radiation, the impact on the building envelope, as well as the air environment, determines the environment of the premises.

Analysis of the climate of cities in the southern region of the CIS on long-term data reveals the presence of hot-calm climate, which is $40 \ldots 70 \%$ of weather conditions in many cities of Central Asia and the republics of the Caucasus. Summer lasts 4 months, during the day in the summer is dominated by high intensity of solar radiation (up to $950 \mathrm{~W} / \mathrm{m}^{2}$ ) and the temperature in the shade (up to $+45^{\circ} \mathrm{C}$ ), weak wind (up to $3 \mathrm{~m} / \mathrm{s}$ ). Similar climatic conditions are also characterized by many cities of the "broad belt" from China to the United States, including Pakistan, Afghanistan, India, Iran, Iraq, Syria, Palestine, North Africa, South America, Spain and others.

Climate analysis of the territory of Asian, African, American and European countries also shows the presence of cities in them, characterized by a long hot calm climate and a relatively short winter period. In buildings with similar climatic conditions open mode of operation of the premises is mainly used.

The only correct way to organize the ventilation of buildings in extreme hot-calm climate conditions is a rational space-planning and architectural design solutions of buildings with the account of the conditions of insolation of their surfaces.

Domestic and foreign scientists have made a great contribution to the field of thermal and air modes of buildings [3-14]. Normative documents and recommendations in this field have been developed $[15,16]$.

Despite the large number of studies in the field of construction aerodynamics, the issue of ventilation of premises under the influence of gravitational pressures is not fully resolved. 
The issue of natural aeration of premises is particularly acute in cities with hot-calm climate conditions, where ventilation of premises due to wind pressure is practically absent.

Natural ventilation of the environment of residential buildings is due to the heat and mass exchange of internal and external air. The intensity of air exchange is largely dependent on the speed of convective flows of the near-wall air layer. During the day, on the insolated side of the facade there are upward convection currents of air, and on the shadow - downward. Due to the constant heating of one or more facades simultaneously there is a natural circulation, cooler air enters the place of the ascending.

In residential buildings, natural air exchange is the main means of maintaining the necessary micro-environmental conditions in the premises.

\section{Results of optimum design}

In order to identify the process of aeration of buildings, due to the heat pressure formed under the condition of insolation of facades and rooms, as well as the development of the theoretical position of thermal aeration of buildings, full-scale studies on the indicators of the microclimate were made: the surface temperature of the walls, air in the rooms and the wall layer over the entire height of high-rise residential buildings of different orientation; the strength and direction of the convective flows on the wall layer of insolated and shaded walls. At the same time, the heating temperature of the insolated walls reached up to $+58 \ldots+65^{\circ} \mathrm{C}$, and the shadow one - only up to $+26^{\circ} \mathrm{C}$. At that time, the temperature of the near-wall air layer of the insolated facades reached up to $+50^{\circ} \mathrm{C}$, the shadow one up to $+30^{\circ} \mathrm{C}$; the air temperature in the rooms facing the irradiated facade reached up to $+32 \ldots+33^{\circ} \mathrm{C}$, in the room of the shadow side-up to $+28^{\circ} \mathrm{C}$. Near the insolated wall, the formation of a powerful upward convective air flow was observed at a speed of up to $3,8 \ldots 5,0 \mathrm{~m} / \mathrm{s}$ in the shadow of the downward flow at speeds up to $0,6 \mathrm{~m} / \mathrm{s}$ (fig. 1 ).

During the open mode of operation of the apartments, full-scale observations of the movement of cool air from the side of the room facing the shadow facade, towards the room facing the insolated façade were made. Further, continuing the path, the air mass through the window openings merged with the General convective flow of the wall layer of the irradiated facade (fig.2).

Depending on the thermal qualities of the building envelope, the solar radiation coming to them is transformed, determine the thermal state of the vertical walls, roofs and adjacent underlying surfaces of the territories, and as a result, the power and mobility of convective flows in the area of housing.

The calculation of the average velocity of the convective flow in $\mathrm{m} / \mathrm{s}$ directed from the heated wall during insolation is performed according to the formula

$$
U_{K}=2 \cdot \sqrt[3]{\frac{g q z}{C_{p} \rho_{\infty} T_{\infty}}} \cdot \sin \alpha
$$

where $\mathrm{q}$ - the flow of convective heat directed from the heating wall, $\mathrm{W} / \mathrm{m}^{2} ; g$ - acceleration of free fall, $\mathrm{m} / \mathrm{s}^{2} ; \quad C_{p}$ - heat capacity of air, $\mathrm{kJ} / \mathrm{kgK} ; \rho_{\infty}-$ ambient air density, $\mathrm{kg} / \mathrm{m}^{3} ; T_{\infty}$ ambient air temperature outside the zone of convective flow, $\mathrm{K} ; z$ - height, $\mathrm{M}$. 
a

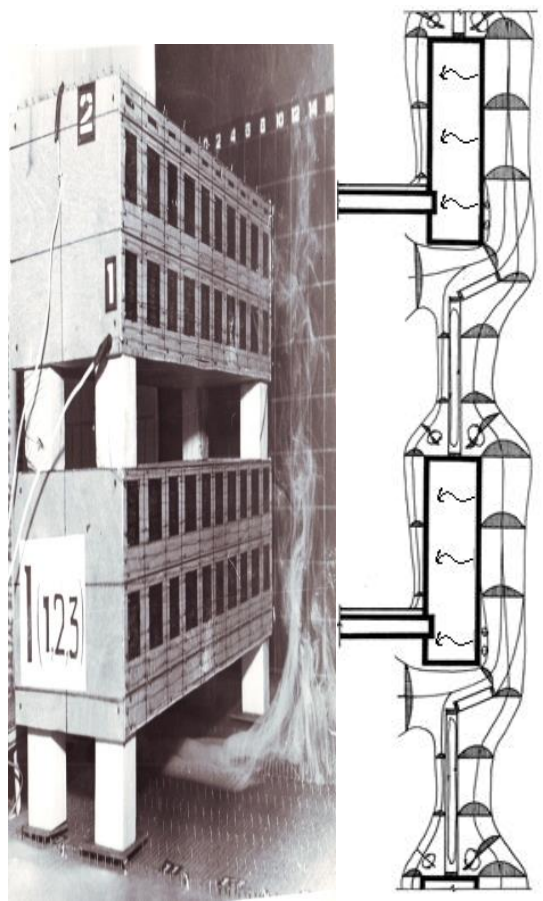

$\mathrm{b}$

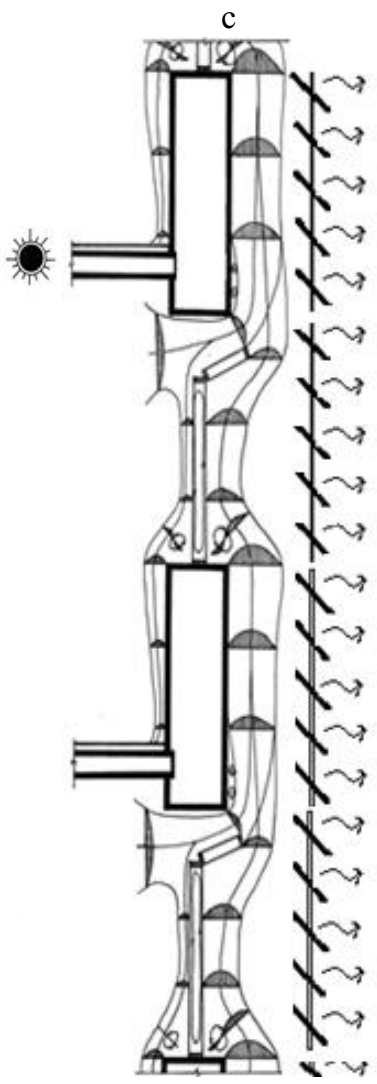

Fig. 1. The aeration of the near-wall layer of air and premises buildings: a-physical model, thermodynamic and aerodynamic processes, b, c-scheme of air flow of the room with a wall convective flow without and with sun protection devices.

For residential buildings erected in calm cities, the only means to improve environmental discomfort is the development of local winds of thermal origin in the micro-ecological shell of the building with the help of targeted use of heat-wind regime by architectural and construction means, removing from the room and dissipating negative emissions into the upper atmosphere. The role of the active surface of the building and its insolation conditions in the formation of a favorable environmental environment of the premises is significant. When the vertical walls and roof of the building are insulated, a micro-ecological shell is formed around it, which differs from the background environmental and climatic factors by its own stationary heat-wind and radiation parameters. Micro-ecological shell of the building, along with solar radiation, the impact on the building envelope, as well as the air environment, determines the environmental environment of the premises.

Natural ventilation of the environment of residential buildings is due to the heat and mass exchange of internal and external air environment. The intensity of air exchange is largely dependent on the speed of convective flows of the near-wall layer of microecological air. The formation of excess pressure near the external surfaces of the building under the influence of natural gravitational forces during the insolation period is presented in the table and in fig.3, table. 


\section{Northern facade}

\section{East facade}

Start of insolation $12 \mathrm{~h} 00 \mathrm{~min}$ End of insolation $18 \mathrm{~h} 20 \mathrm{~min}$

Duration of insolation $8 \mathrm{~h} 20 \mathrm{~min}$

\section{West facade}

Start of insolation $5 \mathrm{~h} 40 \mathrm{~min}$

End of insolation $12 \mathrm{~h} 00 \mathrm{мин}$

Duration of insolation

$8 \mathrm{~h} 20 \mathrm{~min}$

\section{South facade}

Start of insolation $8 \mathrm{~h} 30 \mathrm{~min}$

End of insolation $15 \mathrm{~h} 30 \mathrm{~min}$

Duration of insolation

$7 \mathrm{~h} 00 \mathrm{~min}$

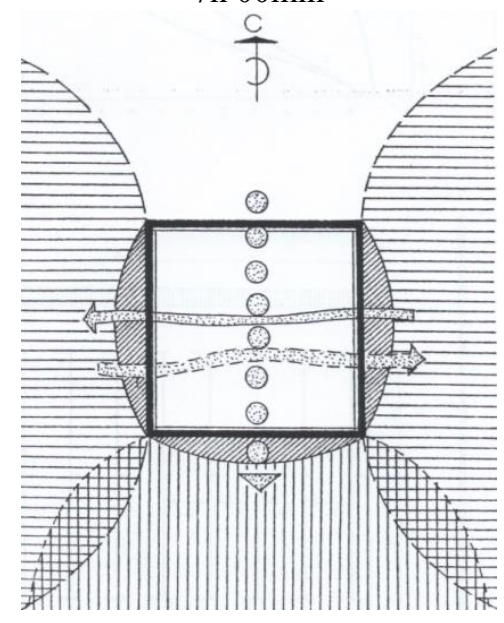

Fig. 2. Aeration of buildings due to thermal head: - zone of heat-wind disturbance from insolated wall; $\bar{E}$ - zone of heat-wind disturbance from the inspected local area; $\because$ 여영 direction of air. 


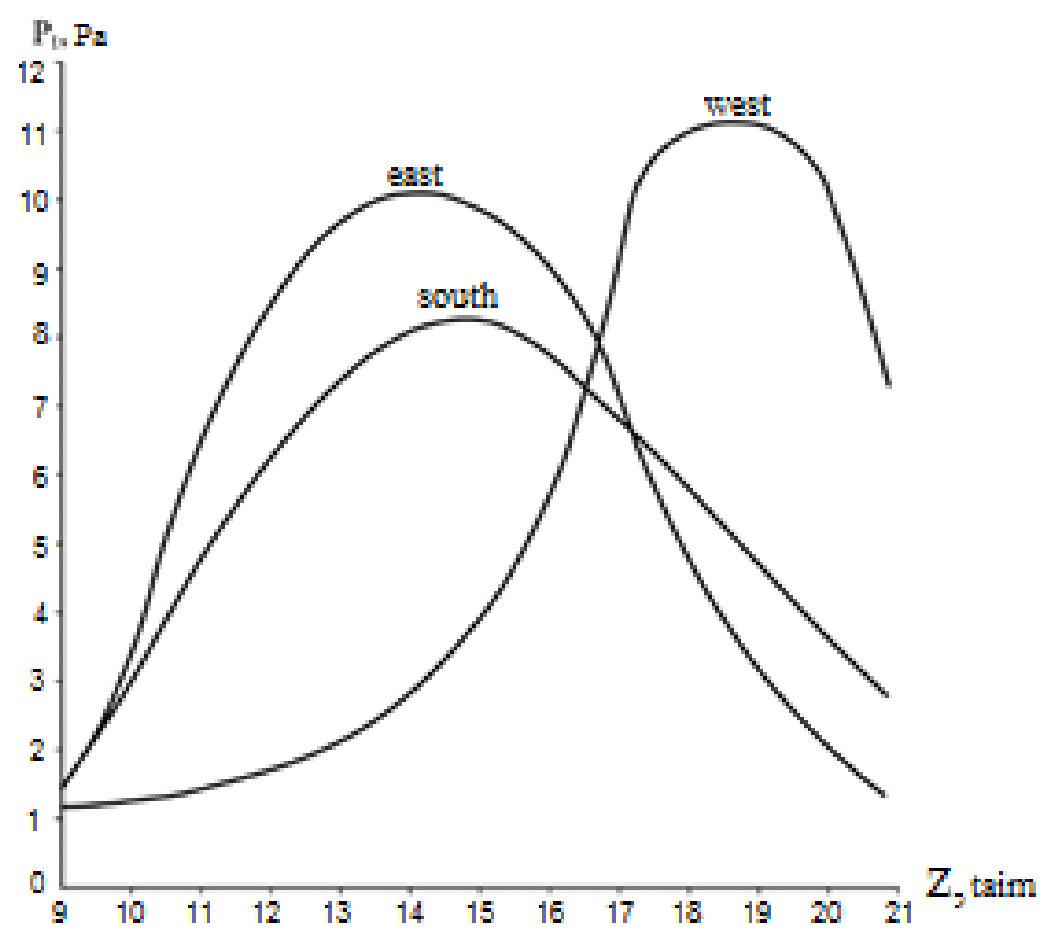

Fig. 3. A graph of the gravitational pressure on the walls of different orientation.

As practice shows the use of exhaust ventilation ducts, provided in the process of design and construction, that during the operation of residential buildings, they do not always provide for the rules of natural ventilation due to a number of objective reasons and most often there is a process of reverse air flow in the room of different floors. In this regard, the role of aeration of premises by ventilation through the window openings is appropriate.

\section{Results}

Improve the environmental characteristics of the air environment of premises with the help of aeration, should be considered simultaneously mode of the building wall and the adjacent underlying surface areas. Field studies conducted in a calm and hot summer days showed that the natural convective updrafts, emerging from a tall building over and adjacent to the building territory, with their exposure, merge creating a more powerful convective upward flow of air with large rates of speed (up to $3 \ldots .5 \mathrm{~m} / \mathrm{s}$ ) and temperature (up to $50 \mathrm{oC}$ ), the adjacent air mass outside the building and inside the room with the corresponding negative components due to infiltration and exfiltration is set in motion.

The results of the study allowed us to create a physical and mathematical model of the heat-wind processes of the wall air layer at different degrees of insolation of the facades of buildings and to identify the role of gravitational convection of the wall air layer in the aeration of buildings. 
Table 1. Aeration of buildings premises at the level of 9-floor at through ventilation under the influence of gravitational pressure.

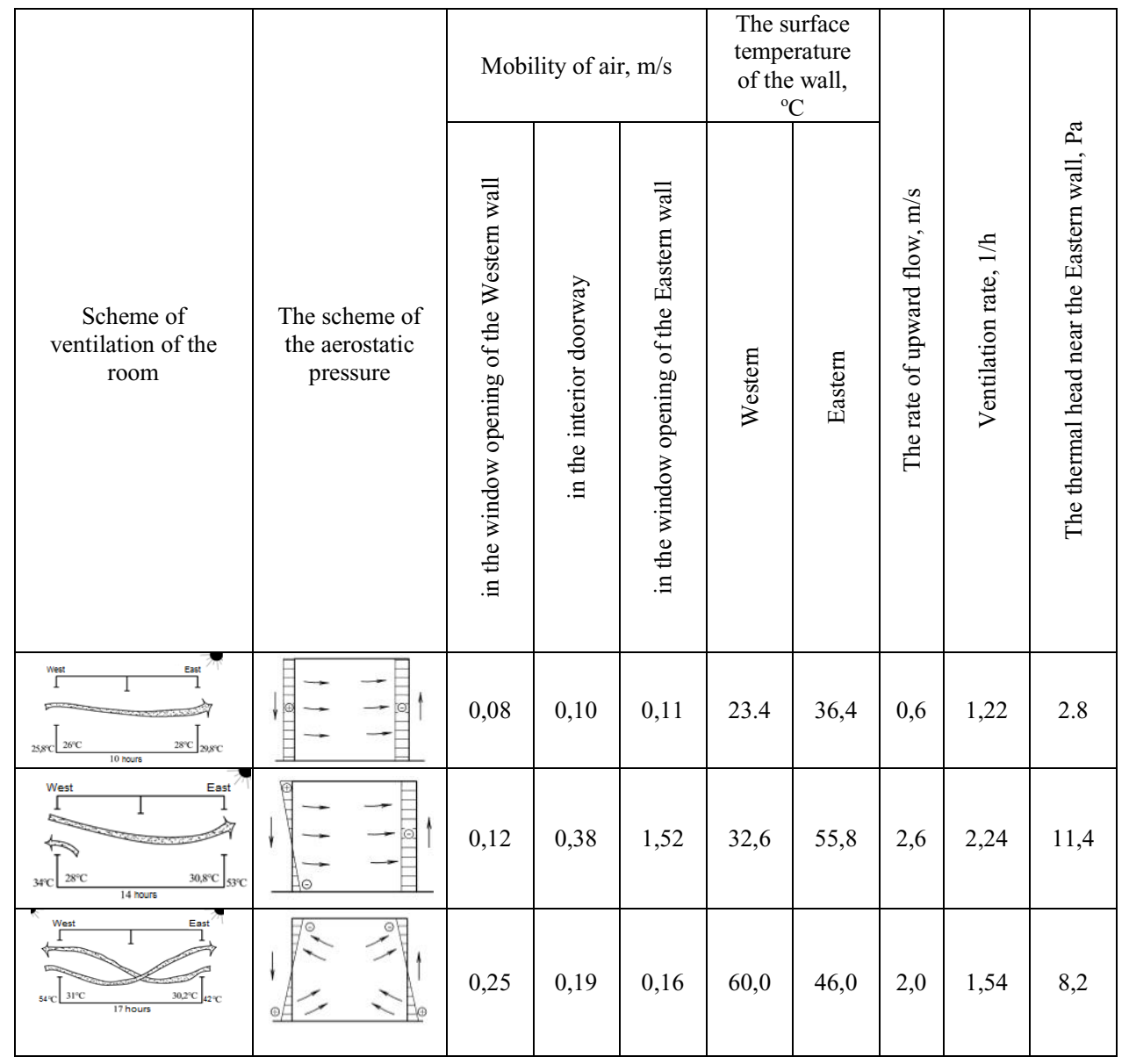

\section{Conclusion}

Summing up the above analysis, it should be noted that to improve the ecological environment of buildings, erected in calm cities in the purposeful destruction and dispersal of negative impurities formed during operation of buildings, local thermal origin emerging from high-rise buildings is significant, which is achieved by architectural and urban planning tools. To do this, it is necessary at the design stage of a residential building, to lay the following foundations, which should include the marked space-planning and architectural design solutions of buildings:

\subsection{Planning solution of the interior space}

- Planning of the apartments, providing cross-ventilation;

- solution of buildings with a column of spatial first intermediate floors, designed for effective ventilation of the wall layer of air and thus the premises of buildings; 
- the removal of ventilation ducts closer to the outer wall and the provision of attached to the facade thermosyphon ventilation shafts, contributing to the ventilation of the premises of the building;

- a coating solution of the atrium, mines vertical ventilating louver shielding with canopies, contributing to the development of convective flow above the

\subsection{Space-planning solution of buildings}

- In order to achieve the maximum duration of insolation required to increase the thermal contrast of the outer surfaces of the walls, it is recommended to Orient the long facade of buildings to the South and South-West, providing sun protection devices and their removal behind the facade line at a distance;

- the solution of volume plastic facades-smooth or maximum dismemberment of the vertical facade, the use of protruding summer rooms, local and crowning cornices, canopies and canopies streamlined airflow vertically shape;

- development of the project "solar house" with passive and active system of solar energy based on the principles of the effect of aerodynamic traction of its enclosing structures;

- identification of the form of buildings and their load-bearing enclosing structures having aerodynamic effect, providing natural aeration of buildings;

- to design underground Parking for high-rise residential buildings, which have connection with the vertical ventilation shaft, which has no connection with the internal spatial environments of floor-to-floor premises.

\subsection{The design of walls of buildings}

- To improve the environmental factors in the room, the activation of convection flows from the active surface of the building and at the same time less overheating of the premises, the insolated wall and roof should be specially calculated and designed to ensure maximum thermal activity of the outer surface of the wall and its minimum thermal conductivity;

- use of solid walls with scales, in the form of vertical along the length of the facade, triangle, parallelepiped, semicircle and other facing forms of the outer surface;

- use of walls with additional solid over the entire height of the building or the height of each floor screen;

- provision of layered walls on the side of the insolated facade or along the perimeter of buildings consisting of two outer structural layers and an intermediate air layer;

- application of walls with non-inertial selective surfaces with high thermal activity and heat resistance;

- the use of walls with dissected edges. These ribs can be used as the walls of the loggias of multi-storey buildings, serve at the same time as sun screens for light openings;

- solution of window blocks with a medium-weighted structure with opening of the upper half of the window block outward from the side of the irradiated façade;

- define the texture and color of the facade.

These methods and means of architecture are based on the effective use of solar energy and building materials, structures for the organization and programming of heat-intensive active surfaces of buildings, which are intended for pumping air and impurities contained in it from one cool volume of the room to another warm, from another room to the external environment.

Thus, the possibility of removing negative substances from the premises of the building with the help of local winds of thermal origin in calm cities, which is the key to improving 
the environmental environment inside the premises and adjacent to the building area. Systematization of aeration of premises by space-planning and architectural-constructive solutions, with rational use of solar energy and the mechanism of thermodynamic and aerodynamic processes allows to predict and regulate the conditions of ventilation of the premises, improving the micro-ecological environment, and is the guidance of designers and specialists in the field of architectural and urban-ecological design.

\section{Acknowledgements}

The work was carried out in accordance with the research plan of the department "Construction, function and environment in the architecture of buildings and cities".

\section{References}

1. A.P. Dubrov, Basics of life safety 8, 44-49 (2011)

2. E. Pichugin, Housing and utilities 8/9, 31-35 (2015)

3. V.N. Bogoslovsky, Construction Thermophysics (High school, Moscow, 1982)

4. E.I. Retter, Architectural and construction aerodynamics (Stroyizdat, Moscow, 1985)

5. F.L. Serebrovsky, Aeration of populated areas (Stroyizdat, Moscow,1985)

6. V. P. Titov, Housing construction 5, 2-6 (1968)

7. G.V. Shelehovsky, The climate of southern cities (Izd. Acad. Med. Sci, Moscow, 1948)

8. I.A. Shepelev, Aerodynamics of air flow in the room (Stroyizdat, Moscow, 1978)

9. M.S. Myagkov, Y.D. Gubernsky, L.I. Konova, V.K. Lickevich, City, architecture, human and climate (Architecture-C, Moscow, 2007)

10. Y.A. Tabunshchikov, M.M. Brodach, Mathematical modeling and optimization of thermal efficiency of buildings (AVOK-PRESS, Moscow, 2002)

11. A.A. Rizka, G.P. Henze, Energy and Buildings 42(10), 1711-1718 (2010)

12. P. Louka, S.E. Belcher, R.G. Harrison, J. of Wind Engineering and Industrial Aerodynamics 74-6, 485-493 (1988)

13. J. Allegrini, V. Dorer, J. Carmeliet Building and Environment 59, 315-326 (2013)

14. A.J. Arnfield, Two decades of urban climate research: A review of turbulence, exchanges of energy and water, and the urban heat island 23(1), 1-26 (2003)

15. MGSN 1.04-2005 Temporary rules and regulations of planning and building design of sites of the territory of high-rise buildings-complexes, high-rise town-planning complexes in the city of Moscow

16. Recommendations for the assessment and management of wind regime residential development/urbanology Department of CSRI of town planning of Gosgrazhdanstroy (Stroyizdat, Moscow, 1986) 